\title{
INIBIÇÃO DE ELASTASE POR EXTRATOS DE CORDIA SUPERBA: UM ESTUDO IN VITRO
}

\section{ARTIGO ORIGINAL}

BARBOSA, Karen Eduarda ${ }^{1}$, SANTOS, Jorge Alexandre Nogueira ${ }^{2}$

BARBOSA, Karen Eduarda. SANTOS, Jorge Alexandre Nogueira. Inibição de elastase por extratos de cordia superba: um estudo in vitro. Revista Científica Multidisciplinar Núcleo do Conhecimento. Ano 06, Ed. 06, Vol. 12, pp. 40-47. Junho de 2021.

ISSN:

2448-0959,

Link de acesso: https://www.nucleodoconhecimento.com.br/biologia/cordia-superba, $\quad$ DOI: 10.32749/nucleodoconhecimento.com.br/biologia/cordia-superba

\section{RESUMO}

As proteases desempenham papéis fisiológicos em seres humanos e quando tem sua atividade desregulada podem gerar diversos problemas e enfermidades. A atividade proteolítica aumentada da elastase, uma serino protease produzida pelo pâncreas e neutrófilos, está relacionada com algumas com envelhecimento precoce da pele e algumas enfermidades como enfisema pulmonar e fibrose cística. Tendo em vista que plantas produzem diferentes classes de compostos bioativos, o presente estudo teve como objetivo avaliar o efeito inibitório de extratos brutos aquosos e etanólicos da planta Cordia Superba sobre a atividade enzimática da elastase. Ambos os extratos apresentaram relevante inibição sobre a atividade proteolítica da elastase. $O$ extrato aquoso apresentou porcentagem de inibição máxima de 99\% na concentração de 440

\footnotetext{
${ }^{1}$ Graduanda de Licenciatura em Ciências Biológicas.

${ }^{2}$ Graduação em Química pela Universidade Federal de São Carlos, doutorado em Bioquímica pela Universidade Federal de São Paulo e pós- doutorado em Bioquímica, com ênfase em Enzimologia.
}

$\mathrm{RC}: 89088$

Disponível em: https://www.nucleodoconhecimento.com.br/biologia/cordia-superba 
$\mu \mathrm{g} / \mathrm{ml}$ e IC 50 de $77,3 \pm 16,4 \mu \mathrm{g} / \mathrm{ml}$.O extrato etanólico inibiu com uma porcentagem máxima de 73\% na concentração de $308 \mu \mathrm{g} / \mathrm{ml}$, com IC 50 de 154,1 $\pm 26,5 \mu \mathrm{g} / \mathrm{ml}$. Em conclusão, os resultados sugerem que os extratos brutos de Cordia Superba podem ser uma boa fonte para prospecção de inibidores da elastase.

Palavras-chave: Enzimas, elastase, inibição

\section{INTRODUÇÃO}

As proteases, proteinases ou peptidades compreendem um grupo de enzimas hidrolases responsáveis pela catálise das reações de hidrólise das ligações peptídicas presentes em proteínas ou peptídeos, por meio de modificações seletivas (WHITAKER, 1994; LOPEZ- OTÍN, 2002; GURUMALLESH et al., 2019).

Por meio do processamento proteolítico, essas enzimas irão permitir um grande número de processos fisiológicos entre os quais destacam: digestão proteica, reprodução, coagulação sanguínea, sistema Kallikrein-Kinin e fibrinólise (OTíN e BONDE, 2008). Também são capazes garantir a execução de uma série de funções celulares por meio das reações em cascata dentre as quais destacam-se a homeostase e a inflamação (RAO et al., 1998). No entanto, se não controladas, podem gerar uma série de patologias em humanos, desencadeando enfermidades como enfisema pulmonar, trombose, diabetes, artrite e câncer (RAWLINGS et al., 2004; DI PAOLO et al., 2019).

As proteases apresentam são classificadas de acordo com suas funções, e quanto ao mecanismo catalítico podem ser classificadas em sete classes: aspartil-, cisteíno-, glutamil-, metalo-, serino- e treonino e atualmente as asparagino peptídeo liaseproteases (RAWLINGS et al., 2011; CAVAILLON e SINGER, 2018). Dentro das serinoproteases, encontra-se a elastase, enzima produzida pelo pâncreas e pelos neutrófilos, com alto potencial na degradação de uma variedade de proteínas da matriz extracelular, entre as quais destacam-se a fibronectina, colágeno, elastina,

RC: 89088

Disponível em: https://www.nucleodoconhecimento.com.br/biologia/cordia-superba 
lamininas e proteoglicanos, bem como proteínas do plasma (BIETH, 1986; SIEDLE et al., 2003).

Essa enzima tem sua atividade regulada por uma inibidores proteicos endógenos, dentre elas a glicoproteína denominada $\alpha$-1-antitripsina (AAT) codificada no gene SERPINA1, locus Pi, localizado no braço longo do cromossomo 14. Em situação normal, ocorre a ligação da enzima com seu principal inibidor ocorrendo a destruição e posterior inibição de ambas as moléculas (HUNTINGTON et al., 2000). Sem a presença do seu inibidor natural, decorrentes de fatores como mutação, por exemplo, a elastase em abundância gera lesões teciduais, já que é liberada pelos neutrófilos em processos inflamatórios (GADEK, 1990; JOHANSSON, 2002).

Uma vez que a elastase é a principal responsável pela degradação da elastina e do colágeno da matriz; e essas proteínas mediam a integridade estrutural e elasticidade da pele, ressalta-se que as depleções exacerbadas de colágeno e elastina contribuem para rugas indesejáveis e envelhecimento precoce. Em fumantes, observa-se o incremento da ação proteolítica da elastase sobre a elastina, decorrente do aumento do número de neutrófilos no pulmão (BARNES, 2003). Por essa razão, a pele tornase mais espessa e fragmentada, gerando também um quadro de envelhecimento precoce (SUEHARA et al., 2006). Além disso, se não controlada no pulmão, a elastase ainda é capaz de gerar um quadro de enfisema, asma, lesão pulmonar aguda ou fibrose cística (ABBOUD e VIMALATHAN, 2008).

A prospecção de moléculas bioativas a partir de produtos naturais encontram em plantas uma fonte promissora de prospecção, uma vez que as espécies vegetais se caracterizam por fácil obtenção e baixo custo (OLIVEIRA et al., 2008). Uma vez que as plantas coevoluíram com microrganismos, insetos, nematóides, aves e mamíferos, foram capazes de desenvolver mecanismos de defesa para se protegerem de ataques de herbívoros e patógenos (HICKS, 1997; TREMACOLDI, 2009). Dessa forma, as plantas são capazes de desencadear uma série de 
mecanismos bioquímicos que auxiliam na sua sobrevivência, entre os quais se destacam a produção de inibidores de proteases (PILON, 2016).

A espécie Cordia Superba, conhecida popularmente como babosa branca, pertence à ordem Boraginales e à família Boraginaceae. Estudos apontam que as espécies de Cordia são utilizadas na medicina popular em todo o mundo. No nordeste do Brasil essas plantas são utilizadas para tratar sintomas de reumatismo, menstruação dolorosa e dispepsia (DA SILVA et al., 2004; COSTA et al., 2008). Nesse sentido é que se evidencia o objetivo deste trabalho que foi avaliar os efeitos de extratos aquosos e etanólicos brutos dos frutos de Cordia Superba sobre a atividade proteolítica da enzima elastase.

\section{MATERIAIS E MÉTODOS}

Os extratos foram preparados a partir da polpa dos frutos de Cordia superba, que foram coletados na fazenda escola do IFSULDEMINAS, pertencente ao município de Inconfidentes, Minas Gerais.

A polpa foi coletada, seca em estufa, sendo que $5 \mathrm{~g}$ desta foram misturados com 50 $\mathrm{ml}$ de água destilada, e colocada em repouso por 12 horas. O material obtido foi filtrado em papel Whatman ํo 1 para a obtenção de um líquido transparente. Depois, também se preparou o extrato etanólico, pelo mesmo procedimento, no entanto, usou-se etanol $95 \%$.

Para os ensaios de inibição, elastase do pâncreas de porco (E.C 3.4.21.36, $\geq 4 \mathrm{U} / \mathrm{mg}$ ) na concentração de $1 \mu \mathrm{g} / \mathrm{ml}$ foi incubada com diferentes concentrações dos extratos aquoso e etanólico por 30 minutos em tampão fosfato de sódio $100 \mathrm{mM}, \mathrm{pH} 8$, à temperatura ambiente. Após esse tempo de incubação, o substrato Succinil-ala-alaala-p-nitroanilida na concentração $5 \mathrm{mM}$ foi adicionado ao meio reacional. Depois de 5 minutos a reação foi paralisada pela adição de ácido acético 30\% e a concentração de p-nitrofenol livre foi determinada medindo absorbância do meio reacional a $410 \mathrm{~nm}$ através de um espectrofotômetro utilizando-se cubetas de plástico com caminho RC: 89088

Disponível em: https://www.nucleodoconhecimento.com.br/biologia/cordia-superba 
óptico de $10 \mathrm{~mm}$ e volume de $1 \mathrm{ml}$ (OKADA et al., 1981; KAPADIA e THOMSON, 1979). A porcentagem de inibição foi calculada através da equação:

$\%$ inibição $=\mid$ Abs controle - Abs extrato $\mid /$ Abs controle $\times 100 \%$

O parâmetro de inibição IC50 foi calculado pela regressão não linear do plote \% de inibição versus concentração de extratos utilizando-se o software Grafit 5.0 (LEATHERBARROW, 1992). Todas as medidas foram realizadas em triplicata. Os dados foram apresentados em termos de média \pm desvio padrão.

\section{RESULTADOS E DISCUSSÕES}

Os extratos de Cordia Superba utilizados neste trabalho foram capazes de inibir a atividade enzimática da elastase, como mostrado no gráfico abaixo. Para o extrato aquoso, observou-se inibição de $97 \%$ na concentração de $440 \mu \mathrm{g} / \mathrm{ml}$ (figura 1), com IC50 de $77,3 \pm 16,4 \mu \mathrm{g} / \mathrm{ml}$.

RC: 89088

Disponível em: https://www.nucleodoconhecimento.com.br/biologia/cordia-superba 
Figura 1. \% de inibição da elastase por extrato aquoso de Cordia Superba. Barras de erros são expressos como desvio padrão, $\mathrm{n}=3$.

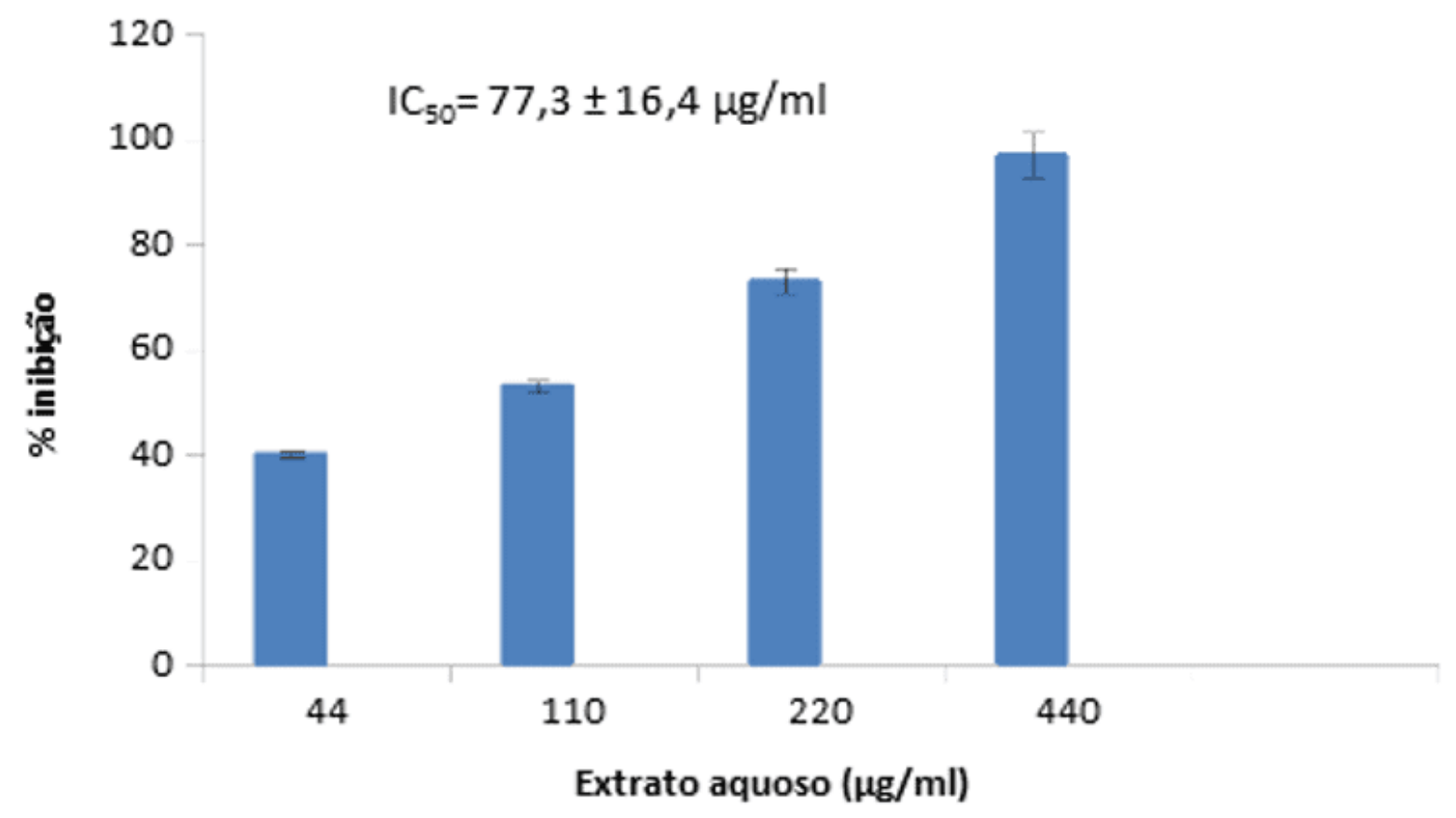

Já para o extrato alcóolico, o potencial de inibição foi um pouco maior. Verificou-se a inibição de $73 \%$ na concentração de $308 \mu \mathrm{g} / \mathrm{ml}$ (figura 2), com IC 50 de 154,1 $\pm 26,5$ $\mu \mathrm{g} / \mathrm{ml}$.

RC: 89088

Disponível em: https://www.nucleodoconhecimento.com.br/biologia/cordia-superba 
Figura 2. \% de inibição da elastase por extrato etanólico de Cordia Superba. Barras de erros são expressos como desvio padrão, $n=3$.

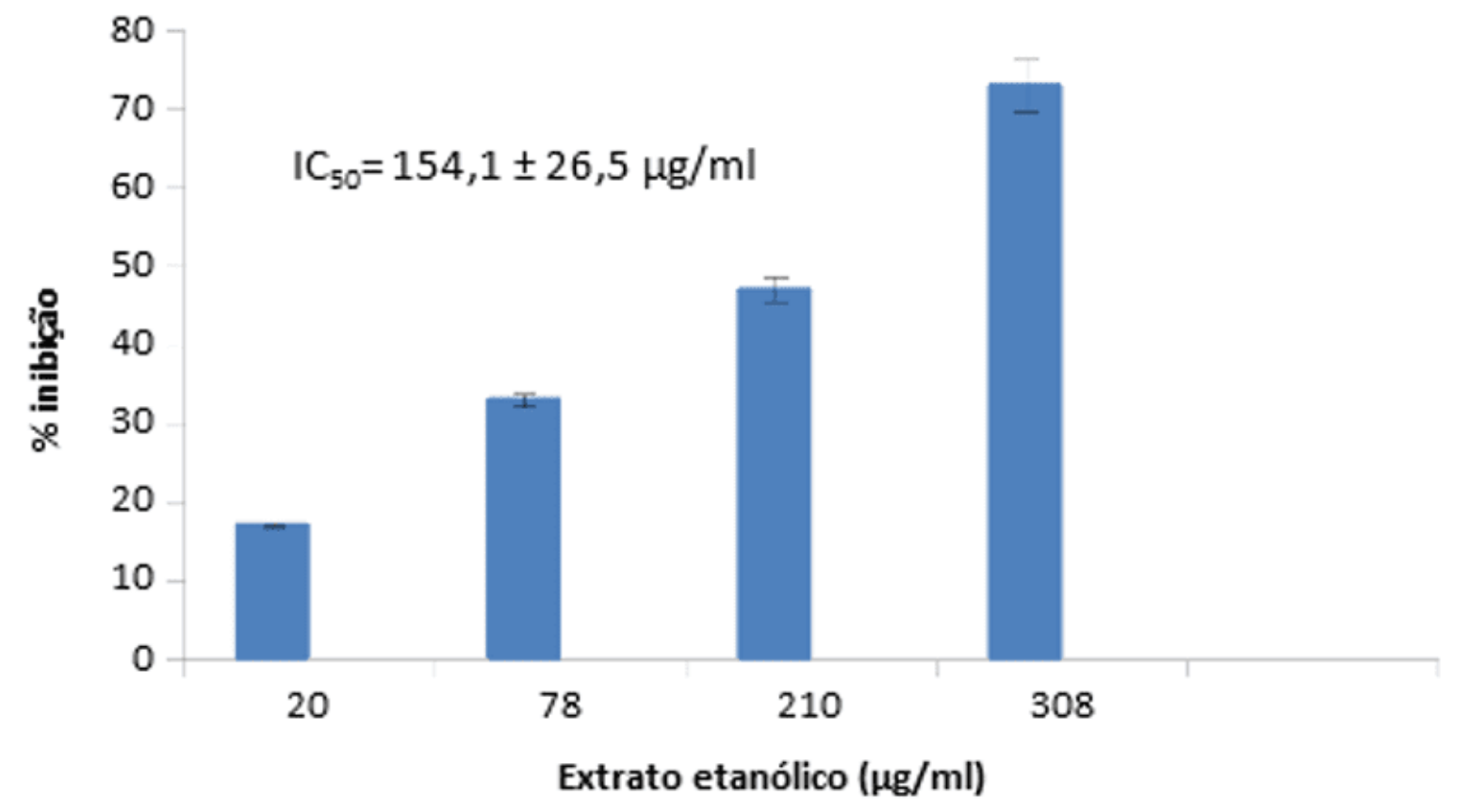

Fonte: autor.

Há registros de que as espécies do gênero Cordia são capazes de produzir metabólitos secundários com atividade analgésica, antiinflamatória, antiartrítica e larvicida (COSTA, 2018). Entre os metabólitos produzidos, destaca-se a classe dos terpenóides, flavonóides e taninos, bem como suas respectivas substâncias químicas e estruturas que podem estar envolvidos no processo de inibição da elastase (GILBERT e FORETTO, 2012; FERREIRA et al., 2015).

\section{CONCLUSÃO}

Os resultados deste trabalho mostraram que os extratos brutos aquosos e etanólicos de Cordia superba apresentaram inibição relevante sobre a atividade enzimática da elastase. A espécie pode ser uma fonte de uma ou mais moléculas que inibem a ação da enzima. Para estudos mais detalhados, é necessário purificar e isolar esses possíveis inibidores, por meio de um fracionamento cromatográfico bioguiado desses extratos.

$\mathrm{RC}: 89088$

Disponível em: https://www.nucleodoconhecimento.com.br/biologia/cordia-superba 


\section{REFERÊNCIAS}

ABBOUD, R.T.; VIMALANATHAN S. Pathogenesis of COPD. Part I: The role of protease-antiprotease imbalance in emphysema. International Journal of Tuberculosis and Lung Diseases. v.12, n.4, p.361-367, 2008.

BARNES, P. J. New concepts in chronic obstructive pulmonary disease. Annual review of medicine, v. 54, n. 1, p. 113-129, 2003.

BIETH, J. G. Elastases: catalytic and biological properties. Academic Press, Orlando (FL), 1986. Pag.219

COSTA, J. F. O.; DAVID, J. P. L.; DAVID, J. M.; GIULIETTI, A. M.; QUEIROZ, L. P.; SANTOS, R. R.; SOARES, M. B. P. Immunomodulatory activity of extracts from Cordia superba Cham. and Cordia rufescens A. DC. (Boraginaceae), plant species native from Brazilian Semi-arid. Revista Brasileira de Farmacognosia. v. 18, p. 11- 15, 2008.

DI PAOLO, C. T.; FILIPPOU , P. S.; YU, Y.; PODA, G.; DIAMANDIS, E. P.; PRASSAS, I. Screening of chemical libraries in pursuit of kallikrein-5 specific inhibitors for the treatment of inflammatory dermatoses. Clinical Chemistry and Laboratory Medicine (CCLM), v. 57, n. 11, p. 1737-1743, 2019.

CAVAILLON, J. M; SINGER, M. (Ed.). Inflammation, 4 volume set: From molecular and cellular mechanisms to the clinic. John Wiley \& Sons, 2018.

DA SILVA, S. A. S.; SOUTO, A. L.; DE FÁTIMA AGRA, M.; DA-CUNHA, E. V. L.; BARBOSA-FILHO, J. M.; DA SILVA, M. S.; BRAZ-FILHO, R. A new arylnaphthalene type lignan from Cordia rufescens A. DC.(Boraginaceae). Arkivoc, v. 6, p. 54-58, 2004.

GADEK, J. E.; PACHT, E. R. The protease-antiprotease balance within the human lung: implications for the pathogenesis of emphysema. Lung, v. 168, n. 1, p. 552-564, 1990.

RC: 89088

Disponivel em: https://www.nucleodoconhecimento.com.br/biologia/cordia-superba 
GILBERT, B.; FAVORETO, R. Cordia verbenacea DC Boraginaceae. Revista Fitos, v.7, n.1., p.17-25, 2012.

GURUMALLESH , P.; ALAGU, K.; RAMAKRISHNAN, B.; MUTHUSAMY, S. A systematic reconsideration on proteases. International journal of biological macromolecules, v. 128, p. 254-267, 2019.

HICKS, D.; DUNCAN, M. J; JONGSMA, M. A.; BOLTER, C. The adaptation of insects to plant protease inhibitors. Journal of Insect Physiology, v. 43, n. 10, p. 885-895, 1997. HUNTINGTON, J. A.; READ, R. J.; CARRELL, R. W. Structure of a serpin-protease complex shows inhibition by deformation. Nature, v. 407, n. 6806, p. 923-926, 2000.

LEATHERBARROW, R.J., GraFit Version 5.0., Erithacus Software Ltd, Staines, U.K. 1992.

MATIAS, E. F. F.; ALVES, E. F., DO NASCIMENTO SILVA, M. K., DE ALENCAR CARVALHO, V. R., COUTINHO, H. D. M., DA COSTA, J. G. M. The genus Cordia: botanists, ethno, chemical and pharmacological aspects. Revista Brasileira de Farmacognosia, v. 25, n. 5, p. 542-552, 2015.

OKADA, Y., MATSUDA, Y., NAGAMATSU, Y. E OKAMOTO, U., Synthesis of substrates specific for human spleen fibrinolytic proteinase. Int. J. Peptide Protein Res., 1981, vol. 17, p. 560-564.

OLIVEIRA, R. B. D., NASCIMENTO, M. V. M., VALADARES, M. C., PAULA, J. R. D., COSTA, E. A., CUNHA, L. C. D. Avaliação dos efeitos depressores centrais do extrato etanólico das folhas de Synadenium umbellatum Pax. e de suas frações em camundongos albinos. Revista Brasileira de Ciências Farmacêuticas, v. 44, n. 3, p. 485-491, 2008.

OTíN, C. L; BOND, J. S. Proteases: Multifunctional Enzymes in Life and Disease. Journal of Biological chemistry, v.283, 30433-30437, 2008.

RC: 89088

Disponível em: https://www.nucleodoconhecimento.com.br/biologia/cordia-superba 
PILON, A.M; VISÔTTO, L. E.; SILVA, C. R.; DE ALMEIDA BARROS, R., DE ALMEIDA OLIVEIRA, M. G. Resposta bioquímica e comportamental de Anticarsia gemmatalis ao inibidor de serino protease benzamidina. Caderno de Ciências Agrárias, v. 8, n. 1, p. 82-89, 2016.

RAO, M. B.; TRANKSALE, A. M.; GHATGE, M. S.; DESHPANDE, V. V. Molecular and biotechnological aspects of microbial proteases. Microbiology and molecular biology reviews, v. 62, n. 3, p. 597-635, 1998.

RAWLINGS, N. D.; BARRETT, A. J.; BATEMAN, A. Asparagine Peptide Lyases A seventh catalytic type of proteolytic enzymes. Journal of Biological Chemistry, v. 286, n. 44, p. 38321-38328, 2011.

RAWLINGS, N. D.; TOLLE, D. P.; BARRETT, A. J. Evolutionary families of peptidase inhibitors. Biochemical Journal, v. 378, n. 3, p. 705-716, 2004.

SIEDLE, B.; GUSTAVSSON, L.; JOHANSSON, S.; MURILLO, R.; CASTRO, V.; BOHLIN, L.; MERFORT, I. The effect of sesquiterpene lactones on the release of human neutrophil elastase. Biochemical pharmacology, v. 65 , n. 5, p. 897-903, 2003.

SUEHARA, L. Y.; SIMONE, K.; MAIA, M. Evaluation of facial aging related to cigarette smoking. Anais brasileiros de dermatologia, v. 81, n. 1, p. 34-39, 2006.

THOMSON, A.; KAPADIA, S.K. The specificity of the S1 and S2 subsites of elastase, Eur.J.Biochem, vol.102, p. 311-116, 1979.

TREMACOLDI, C. R. Proteases e inibidores de proteases na defesa de plantas contra pragas. Embrapa Amazônia Oriental-Documentos (INFOTECA-E), 2009.

WHITAKER, J. R.; STAUFFER, C. E. Principles of Enzymology for the Food Sciences (2nd edn). Trends in Food Science and Technology, v. 5, n. 9, p. 304-304, 1994. 
Enviado: Março, 2021.

Aprovado: Junho, 2021.

RC: 89088

Disponível em: https://www.nucleodoconhecimento.com.br/biologia/cordia-superba 